\title{
Endodontic management of an unidentified foreign body in a maxillary central incisor of a HIV-positive patient
}

SADJ July 2019, Vol. 74 No. 6 p325 - p328

CH Jonker', PJ van der Vyver ${ }^{2}$

\section{SUMMARY}

The Human Immunodeficiency Virus (HIV) has been a focal point of investigation over the last few years. Consideration of endodontic treatment in an HIV-positive patient needs a calculated approach as the choice of materials and chemicals may influence the final result. A recent investigation showed that cases presenting with pre-operative pathology during examinations have a significantly lower prognosis after treatment. This clinical case report discusses the treatment approach of an upper left central incisor of an HIV-positive patient. The treatment approach and the outcome after a fifteenmonth follow-up period are outlined.

\section{INTRODUCTION}

Foreign bodies are sometimes lodged inside the root canal system of teeth and can be fortuitously discovered during dental examinations. In reported cases, children are among the patients more often affected by this phenomenon. ${ }^{1}$ The reality is that these foreign bodies are not sterile and act as a potential breeding ground for organisms, which have the ability to cause infections and complications in the future. ${ }^{1}$

Once a foreign body is present inside a root canal system, proper root canal treatment can be compromised due to instrumentation difficulties and obstruction within the path of cleaning and shaping. Once those processes are affected and the root canal system only partially disinfected, the outcome of endodontic treatment can be unpredictable. ${ }^{1}$ The Human Immunodeficiency Virus (HIV) has been a focal point of investigation over the last few years and the development of highly active antiretroviral treatment (HAART) has altered the status of the disease to that of a chronic medical condition.

Author affiliations:

1. Casper H Jonker: BChD (Pret), Dip Odont (Endo), MSc (Pret), PhD; DSC, Division of Endodontics, Department of Operative Dentistry, Sefako Magatho Health Sciences University, Ga-Rankuwa, South Africa.

ORCID Number: 0000-0002-9110-5208

2. Peet J van der Vyver: BChD, PG Dip Dent (Endo), PG Dip Dent (Aesthet Dent), MSc, PhD (Pret), Department of Odontology, School of Dentistry, University of Pretoria, Pretoria, South Africa. ORCID Number: 0000-0003-1951-6042

Corresponding author: $\mathrm{CH}$ Jonker

Department of Operative Dentistry, Sefako Magatho Health Sciences

University, Ga-Rankuwa, South Africa.

Email: casper.jonker@smu.ac.za

\section{ACRONYMS}

HIV: $\quad$ Human Immunodeficiency Virus

HAART: Highly Active Antiretroviral Treatment

MTA: $\quad$ Mineral Trioxide Aggregate

DOM: Dental Operating Microscope

CEJ: Cemento-Enamel Junction

The introduction of HAART therapy has also reduced the morbidity associated with the disease. ${ }^{2}$ According to the available literature, endodontic prognosis in HIVpositive patients is determined by a single important factor, namely the presence of a pre-operative lesion. ${ }^{3}$ Aminoshariae et al. $(2017)^{3}$ report in a very recent publication that cases presenting with pre-operative lesions during examination have a significantly lower prognosis. In these cases the presence of systemic disease (HIV) may play a substantial role.

Consideration of endodontic treatment in an HIV-positive patient needs a calculated approach as the choice of materials and chemicals may influence the final result. The use of Mineral trioxide aggregate (MTA) has been advocated as a very good material for the creation of an apical barrier during endodontic treatment due to its numerous advantages. ${ }^{4}$

The material has the unique ability to form apatite-like interfacial deposits during its maturation phase and will possibly fill voids that are present during obturation. ${ }^{5}$ These interfacial deposits may be responsible for the superior seal created by MTA if it is used as a regular obturation material for the repair of perforations. ${ }^{5}$

The case presented reports on endodontic management of a tooth affected by a foreign body in an HIV-positive patient.

\section{CASE REPORT}

\section{Visit 1}

A 13-year old female patient attended Sefako Makgatho Oral Health Centre for continuation of endodontic treatment of the upper left central incisor. Medical examination revealed that the patient was HIV-positive and on anti-retroviral drug therapy. Dental examination determined that emergency root canal treatment had been attempted approximately one year previously. The temporary restoration was lost soon after the visit, but the patient did not attend further appointments and endodontic treat- 
ment was not completed. The tooth was sealed at home by placing cotton pledgets into the access cavity. The pre-operative radiograph (Figure 1) revealed a large periapical lesion and a foreign object in the apical third.

Treatment consent was obtained before local anaesthetic was administered and the tooth irrigated under strict rubber dam isolation. Large amounts of cotton pledgets were removed from the root canal under examination using the Dental Operating Microscope (DOM) (Carl Zeiss, Oberkochen, Germany).

Length determination was done using an electronic apex locator. Due to previous attempts to clean and shape the canal, no glide path was indicated. The WaveOne Gold Large reciprocating instrument (45/05) (Dentsply Sirona, Ballaigues, Switzerland) was used for canal preparation and it was noted that the apex was wide open. It was decided to pack MTA (Dentsply Sirona, Ballaigues, Switzerland) in order to close the open apex.

The canal was dried with large paper points and calcium hydroxide placed in the canal (Calasept Plus, Nordiska Dental, Sweden) before the access cavity was closed with Ketac Molar (3M ESPE, Seefeld, Germany).
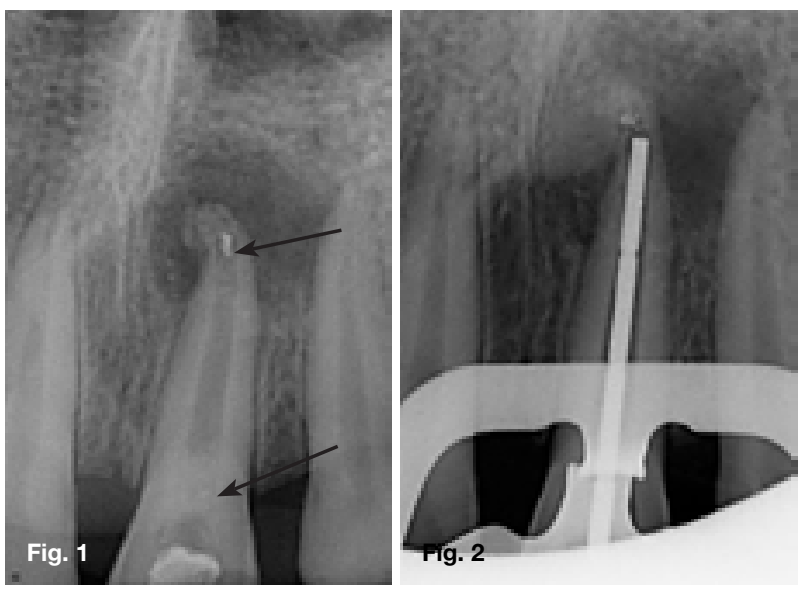

Figure 1. Pre-operative periapical radiograph illustrating foreign object in the maxillary central incisor. Note the large periapical area around the root tip.

Figure 2. Periapical radiograph confirming the fit of a Machtou plugger (Dentsply Sirona). Note that the foreign object moved apically into the periapical tissue.
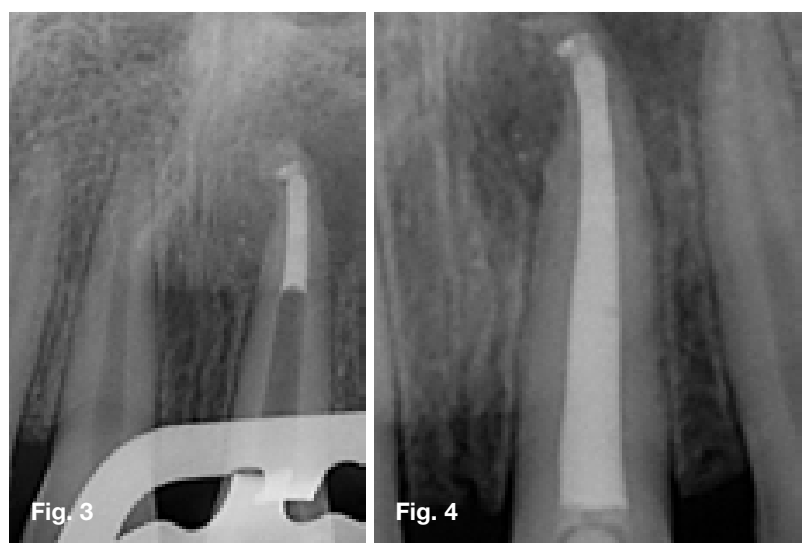

Figure 3. Periapical radiograph showing the apical MTA plug and foreign body at the apex of the tooth.

Figure 4. Completed obturation of root canal system.
The patient was re-scheduled for completion of the treatment on a subsequent visit approximately four weeks later. A request was also made to obtain the latest blood results reporting a CD4 count and HIV viral load.

\section{Visit 2}

The patient reported no discomfort since the previous visit. Blood tests showed the following information:

1. CD45 + White Cell Count of $4.12 \times 109 / L$;

2. CD4\% 42.78\%;

3. Absolute CD4 count of 976 cells/uL;

4. HIV viral load of lower than detectable limit.

The temporary restoration and cotton were removed. SmearClear, a 17\% EDTA solution (Dental Discounts, Rivonia, South Africa) was used as a chelating agent in an effort to remove the smear layer.

The tooth was carefully irrigated with 3.5\% sodium hypochlorite using the EndoActivator (Dentsply Sirona, Ballaigues, Switzerland) to activate the solution. No drainage was noted from the root canal space.

The fit of a Machtou plugger (Dentsply Sirona, Ballaigues, Switzerland) (Figure 2) was confirmed radiographically but it can be noted that the foreign object moved apically into the periapical tissue. The decision was made to leave the foreign object in situ, to incorporate it into the obturation material and to place the tooth under observation. An apical plug of approximately $5 \mathrm{~mm}$ was created (Figure 3 ) and the remaining root canal was obturated using BioRoot RCS sealer (Septodont, Saint-Maur-des-Fosses, France) and heated gutta-percha (Obtura Spartan Endodontics, Algonquin, IL, USA).

The heated gutta-percha was placed in small increments and gently vertically compacted using Machtou pluggers and slight apical pressure. The final obturation was sealed with a glass-ionomer base (Vitrebond, 3M ESPE) at the level of the cemento-enamel junction (CEJ) and a semi-permanent restoration was placed for observation (Figure 4).

\section{Follow-up visits}

At a follow-up visit four weeks later the patient reported no discomfort. The decision was made to review the case again in six months. During this visit the patient was symptom-free with no visible swelling or mobility of the tooth. A periapical radiograph revealed early signs of bone regeneration (Figure 5). The patient was informed that apical surgery might be needed in the future if any foreign body reaction occurs or healing is incomplete. The next follow-up visit was scheduled for three months' time.

The patient was seen again at a nine-month follow-up visit and reported no discomfort. No mobility or swelling was noted. A periapical radiograph revealed good healing of the periapical pathology (Figure 6). The decision was made to schedule a further follow-up in six months to evaluate the healing process. The patient had no discomfort and the coronal restoration was intact. 
A periapical radiograph was taken and it was noted that the periapical radiolucency has increased in size compared with the nine month follow-up periapical radiograph (Figure 7). There was also no history of trauma or untoward complications since the last visit.

The patient and parents were informed that healing was unsatisfactory and that a surgical procedure would be required to remove any foreign objects and investigate the apical region.

\section{DISCUSSION}

Root canals or pulp chambers can be obstructed by a number of foreign materials, which include endodontic files and obturation materials as well as foreign objects lodged inside a tooth by the patient him/herself. ${ }^{1}$ Objects include pencil leads, darning needles, metal screws and many other items..$^{6-8}$ In the case described it was not possible to determine the nature of the object and the patient and parent were unaware of the cause. Chand et al. (2013) ${ }^{1}$ suggest that careful instrumentation is needed to avoid further apical movement of foreign objects.

During removal of cotton remnants in the presented case, the foreign object moved apically although care was taken in the process and careful instrumentation was used. It could be argued that the size of the particle played an important role in the apical movement. Further attempts to remove or dislodge the object increased the possibility of damage to the apical root anatomy and the creation of an irregular, open apex.

Once the decision was made to incorporate the foreign object into the obturation, proper irrigation was needed to create a sterile environment to encourage healing and bone formation. A recent study by Mancini et al. (2013) ${ }^{9}$ compared the efficacies of different irrigation systems for removal of the smear layer in the apical region of infected root canals.
They concluded that the EndoActivator (Dentsply Sirona) and EndoVac (Discus Dental, Culver City, CA) showed superior cleaning $3 \mathrm{~mm}, 5 \mathrm{~mm}$ and $8 \mathrm{~mm}$ from the apex compared with other systems evaluated in the study.

Further, in an effort to create a sterile environment for the obturation phase, the calcium hydroxide intracanal medicament was left in situ for a period of approximately four weeks. Investigation of available literature indicates that a maximum period of four weeks is clinically acceptable before structural changes can be observed in root dentine, leading to possible root fractures. ${ }^{10,11}$

Due to the superior qualities of MTA, the decision was made to use it as an apical plug instead of regular obturation techniques. A barrier of $5 \mathrm{~mm} \mathrm{MTA}$ was created apically according to suggestions in the literature. ${ }^{12}$ MTA as an obturation material is claimed to have numerous benefits, which include superb biocompatibility, a biologically acceptable seal and reduced cytotoxicity. ${ }^{13}$

Bogen and Kuttler (2009) $)^{14}$ advocate the use of MTA as a suitable obturation material after cleaning and shaping and even as a complete fill of the root canal system, which might ultimately increase the long-term prognosis and retention of the tooth.

In this particular case, only a $5 \mathrm{~mm}$ plug was created, with heated gutta-percha filling the remainder of the canal. The gutta-percha could be removed in the future to allow the creation of a proper coronal seal with advocated techniques. Restorability is further complicated by the patient's age, and the choice of restoration will eventually determine the long-term success of this particular case.

According to Siboni et al. (2017),,$^{15}$ the use of BioRoot RCS as an endodontic sealer offers numerous advantages during obturation.
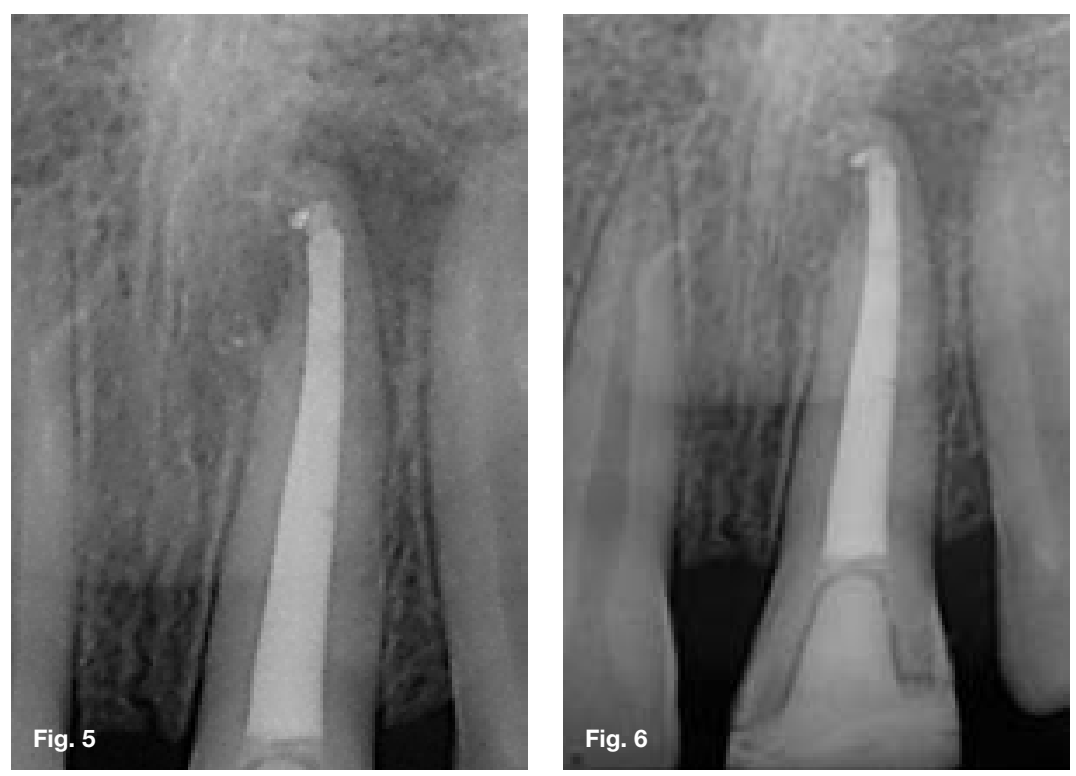

Figure 5. A periapical radiograph taken at six-month follow-up visit.

Figure 6.A periapical radiograph taken at nine-month follow-up visit showing good healing.
Figure 7. A fifteen-month follow-up radiograph showing an increase in size of the periapical pathology.

(n)

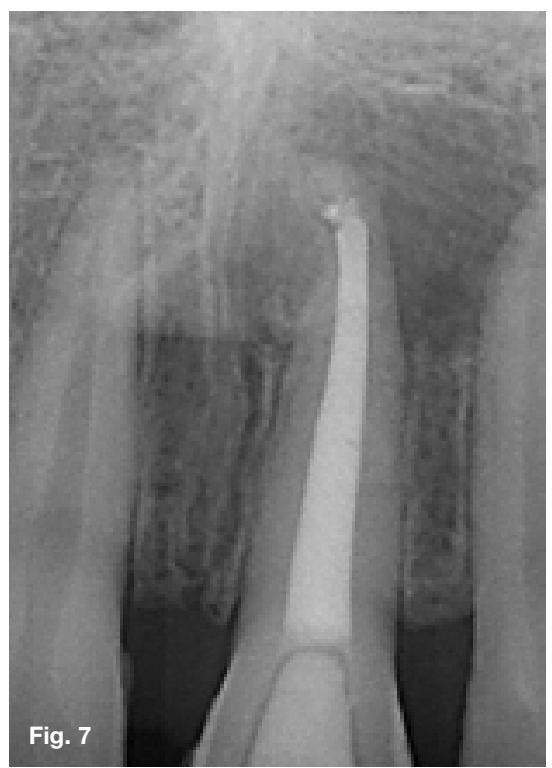


The material is well suited for single cone techniques and cold lateral condensation. The literature indicates that BioRoot RCS has the ability to stimulate the periodontal ligament cells to form angiogenic and osteogenic growth factors. ${ }^{16}$

The sealer can also reduce cytotoxicity and may increase the formation of hard tissue. ${ }^{17,18}$ Authors AriasMoliz \& Camilleri (2016) $)^{19}$ conclude that the sealer has anti-microbial qualities, which is a very important consideration for sterility and healing.

Limited information is available on the relationship between HIV infections and endodontics. HIV infection is characterised by a variety of symptoms and a fastmultiplying virus and, if left untreated, a severely compromised immune response can be expected. ${ }^{20}$

The main targets of the HIV virus are the CD4 cells of the host. As discussed earlier, the presence of apical lesions plays a decisive role in the success of endodontic treatments in HIV-positive patients. Vital cases normally illustrate very good success rates. ${ }^{3}$

In the current case, the prognosis was complicated by the presence of a necrotic root canal system left open for a prolonged period, a large periapical lesion and a foreign object. There is also a high probability that other foreign objects had been extruded beyond the apical foramen by the patient herself.

Fortunately, the patient's HIV status is well controlled, with an absolute CD4 count within normal National Health Laboratory Service limits (530-1300 cells/uL) and the HIV viral load virtually undetectable.

The results obtained in this case are in line with reported findings that the prognoses of endodontically affected teeth are the same for HIV-positive and HIVnegative patients. ${ }^{21,22}$ Observation of the fifteen-month follow-up radiograph revealed that incomplete healing was present.

Although it can only be speculated on the reasons why, the radiographic finding is in line with the conclusions of Aminoshariae et al. (2017). ${ }^{3}$

These authors stated that affected teeth with periapical lesions prior to treatment have a reduced prognosis, therefore requiring further treatment.

\section{CONCLUSION}

The case illustrates a novel approach to the management of a necrotic tooth with a foreign object left in situ in the root, in an HIV-positive patient. The case presented numerous negative factors, contributing towards the final treatment outcome.

These factors were a large apical lesion, a root canal system left open for a long period of time, an HIV-positive patient and a foreign object lodged in the root canal system. The outcome after apical surgery and follow-up healing will be discussed in a future report.

\section{References}

1. Chand K, Joseph S, Varughese JM, Nair MG, Prasanth S. Endodontic management of an unusual foreign body in a maxillary central incisor. J Conserv Dent. 2013; 16: 474-6.

2. Campo J, Cano J, Del Romero J, Hernando V, Rodríguez C, Bascones A. Oral complication risks after invasive and non-invasive dental procedures in HIV-positive patients. Oral Diseases 2007; 13: 110-6.

3. Aminoshariae A, Kulild JC, Mickel A, Fouad AF. Association between systemic diseases and endodontic outcome: A systematic review. J Endod. 2017; 43: 514-9.

4. Holden DT, Schwartz SA, Kirkpatrick TC, Schindler WG. Clinical outcomes of artificial root-end barriers with mineral trioxide aggregate in teeth with immature apices. J Endod. 2008; 34: 812 - 7.

5. Tay FR, Pashley DH. Monoblocks in root canals: A hypothetical or a tangible goal. J Endod. 2007; 33: 391-8.

6. Hall JB. Endodontics - Patient performed. ASDC J Dent Child. 1969; 36: 213-6.

7. Nernst H. Foreign body in the root canal. Quintessenz 1972; 23: 26.

8. Prabhakar AR, Basappa N, Raju OS. Foreign body in a mandibular permanent molar: A case report. J Indian Soc Pedod Prev Dent. 1998; 16: 120-1.

9. Mancini M, Cerroni L, lorio L, Armellin E, Conte G, Cianconi L. Smear layer removal and canal cleanliness using different irrigation systems (endoactivator, endovac, and passive ultrasonic irrigation): Field emission scanning electron microscopic evaluation in an in vitro study. J Endod. 2013; 39: 1456-60.

10. Andreasen JO, Farik B, Munksgaard EC. Long-term calcium hydroxide as a root canal dressing may increase risk of root fracture. Dent Traumatol. 2002; 18: $134-7$.

11. Hatibovic-Kofman S, Raimundo L, Zheng L. Fracture resistance and histological findings of immature teeth treated with mineral trioxide aggregate. Dent Traumatol. 2008; 24: 272-6.

12. Jonker $\mathrm{CH}$, Van der Vyver PJ. Apexification of immature teeth using an apical matrix and MTA barrier material: Report of two cases. S Afr Dent J. 2017; 72: 414-9.

13. Schmitt D, Lee J, Bogen G. Multifaceted use of ProRoot MTA root canal repair material. Pediatr Dent. 2001; 23: 326-30.

14. Bogen G, Kuttler S. Mineral trioxide aggregate obturation: A review and case series. J Endod. 2009; 35: 777-90.

15. Siboni F, Taddei P, Zamparini F, Prati C, Gandolfi MG. Properties of BioRoot RCS, a tricalcium silicate endodontic sealer modified with povidone and polycarboxylate. Int Endod J. 2017; 50: e120-e136.

16. Camps J, Jeanneau C, El Ayachi I, Laurent P, About I. Bioactivity of a calcium silicate-based endodontic cement (BioRoot RCS): Interactions with human periodontal ligament cells in vitro. J Endod. 2015; 41: 1469 -73.

17. Dimitrova-Nakov S, Uzunoglu E, Ardila-Osorio $\mathrm{H}$ et al. In vitro bioactivity of Bioroot ${ }^{\mathrm{TM}} \mathrm{RCS}$, via $\mathrm{A} 4$ mouse pulpal stem cells. Dent Mat. 2015; 31: 1290-7.

18. Prullage RK, Urban K, Schäfer E, Dammaschke T. Material properties of a tricalcium silicate-containing, a mineral trioxide aggregate-containing, and an epoxy resin-based root canal sealer. J Endod. 2016; 42: 784 -8.

19. Arias-Moliz MT, Camilleri J. The effect of the final irrigant on the antimicrobial activity of root canal sealers. J Dent. 2016; 52: $30-6$.

20. Kahn JO, Walker BD. Acute human immunodeficiency virus type 1 infection. N Engl J Med. 1998; 339: 33 -9.

21. Quesnell BT, Alves M, Hawkinson RW Jr, Johnson BR, Wenckus $\mathrm{CR}$, BeGole EA. The effect of human immunodeficiency virus on endodontic treatment outcome. J Endod. 2005; 31: 633-6.

22. Suchina JA, Levine D, Flaitz CM, Hicks MJ. Retrospective clinical and radiological evaluation of non-surgical endodontic treatment in human immunodeficiency virus (HIV) infection. J Contemp Dent Prac. 2006; 7: 1-8. 